\title{
A Longitudinal Exploration of Strategic Isomorphism: The Case of the National Football League
}

\author{
Kenneth M. York and Cynthia Miree \\ Oakland University, MI, USA
}

\begin{abstract}
Within any given industry, firms are faced with the pressure to strive for increased uniqueness. The purpose of the current study is to explore a phenomenon known as strategic isomorphism (or increased homogeneity among firms as a result of deliberate strategic choice). To this end, this research used seven different statistical techniques, to examine performance data within the National Football League (NFL) across fifty-three NFL seasons in an effort to determine if the NFL had isomorphic characteristics (as measured by competitive balance). In testing for presence of competitive balance in the NFL, we found a low standard deviation in winning percentage across teams in the seasons 1960-2012, indicating that the NFL has been a league of teams of nearly equal strength. From a longitudinal perspective we found that the NFL has not been dominated by a few strong teams nor has any single NFL team has been able to maintain dominance across multiple seasons. The current study is one of very few longitudinal studies that examine strategic isomorphism within a competitive context. Its results provide evidence that under certain competitive conditions, striving for increased similarity among competitors may be appropriate strategic choice.
\end{abstract}

Key Words: Institutional theory, strategic isomorphism, competitive balance, sports

\section{Exploring Strategic Isomorphism}

The field of strategic management has its primary interest in understanding both how firms develop and pursue long-term competitive and performance goals within the broader industry and macro environments, and why some firms are able to consistently outperform others (Barney, 2001; Porter, 1996). To aid in this exploration, researchers have utilized a number of organizational theories. Institutional theory, for example, predicts that firms operating in the same organizational field will alter their structures or processes in similar ways based on exogenous demands to be perceived as legitimate by relevant stakeholders and ensure the continued flow of resources (cf., Abrutyn, 2012; Davis, and Marquis, 2005; Bresser and Millonig, 2003). Consequently, firms competing in environments with strong institutional pressures will experience an increase in homogeneity or isomorphism among said firms.

While the choice to pursue or adopt similar structures, policies or other activities may seem counterproductive to achieving a competitive advantage in the marketplace (e.g., Barney, 2001; Peteraf, 1993; Porter, 1996), a number of studies have demonstrated that isomorphism among firms may actually be a deliberate and appropriate strategic choice in some competitive contexts (cf., Fernández-Alles and ValleCabrera, 2006; Deephouse and Carter, 2005; Deephouse, 1996).

Fernández-Alles and Valle-Cabrera (2006) identify a number of paradoxes that result from the juxtaposition of institutionalism with other theoretical frameworks that are used to explore and understand firm behavior. In particular they elaborate and reconcile their identified first paradox that "Differentiation supports and sustains competitive advantage, but conformity to institutional pressures provides legitimacy, resources, and competitive advantage, p. 505," by highlighting the managerial importance of understanding when to pursue differentiation versus conformity within a particular competitive context. They state, "Conformity reduces differentiation but, at the same time, reduces risks associated with the loss of legitimacy and helps in resource acquisition" p. 505.

Corresponding author: Cynthia Miree, $\mathrm{PhD}$, Associate Professor of Management, 413 Elliott Hall, School of Business Administration, Oakland University, Rochester, MI 48309 , Email: miree@oakland.edu

(c) $\mathrm{T}$

This article is distributed under the terms of the Creative Commons Attribution License, which permits unrestricted use and redistribution provided that the original author and source are credited. 
They further argue that one type of isomorphism, known as strategic isomorphism, is a result of intentional strategic choice rather than a "passive" response to institutional pressures (Deephouse, 1996).

In other words, rather than leverage or acquire resources to create a unique competitive position in the environment, a firm will use its resources to gain "social acceptance resulting from adherence to regulative, normative, or cognitive norms and expectations" (Deephouse and Carter, 2005). These studies suggest that strategic isomorphism is a direct result of systematic and intentional strategic decision-making with conformity as a desired outcome and is best understood as a deliberate and calculated attempt to capitalize on a potential competitive opportunity. Further, according to Fernández-Alles and ValleCabrera (2006) it holds as much validity as choosing differentiation as an appropriate competitive strategy. Nevertheless, the firm's ultimate ability to gain a strategic or competitive advantage is dependent in part on how well managers "interpret accurately, and adapt well to institutional pressures..... That is, firms gain an advantage from their superior ability to align themselves with their institutional context" (Fernández-Alles and Valle-Cabrera, 2006, p. 506).

As previously stated, the expectations of external constituents play a vital role in establishing and maintaining legitimacy and its consequent rewards. Thus, the power of external constituents in the institutional context is significant. With this in mind, it is important to remember that the type of external constituent able to exert said power will vary from industry to industry. In the banking industry, regulators might be the most "important" constituents while in the defense industry the government will play a significant role. In an industry like organic foods, consumers may play a vital part of setting cultural norms and product or service expectations and standards. Consequently, organizations seeking legitimacy must understand and attend to the expectations of those that consume sports entertainment if they wish to be perceived as legitimate, thereby ensuring future cash flows in the form of revenue. In the next section we will explore the National Football League and the impact fans (as a key constituent) have on its ability to maintain itself as a strongly desired source of entertainment.

The National Football League and Competitive Balance

The National Football League (NFL) consists of thirty-two teams across two conferences playing over 250 games in the regular season plus playoff games to determine a champion. The NFL's competitive environment is unique in a number of ways. While the NFL's teams compete against each other on the field, the individual owners of the NFL's teams are dependent on each other for the creation of the NFL's entertainment product, exciting football games. In recent years, the NFL has received increased attention in the literature. In particular, some researchers have focused on the presence of "competitive balance" within the sports arena (Sanderson, 2002; Zimbalist, 2002; Grier and Tollison, 1994).

The concept of competitive balance is best understood as a phenomenon wherein games between opponents of comparable ability are valued and consequently "created" to increase the perceived uncertainty of the outcome associated with any given match between two contestants (Sanderson, 2002). Sanderson (2002) further points out that balanced competition may be a necessary condition to maintain fan interest and economic viability. He highlights several examples of contrived conditions that are used to create balance such as the adoption of unbalanced schedules wherein "better teams, based on the previous year's records play more games against stronger opponents and weaker teams face off again each other disproportionately" (Sanderson, 2002, p. 209).

Zimbalist (2002) and Grier and Tollison (1994) also identify several rules that the NFL employs to create competitive balance; specifically, extensive revenue sharing (transferring revenues from larger market teams to smaller market teams), the use of player salary caps, a reverse order drafting process for new players (giving earlier draft picks to teams with worse records), and an unbalanced schedule (better teams this year play other better teams next season in the games not fixed by the scheduling cycle).

While manufacturing competitive balance within the NFL through revenue sharing, salary caps, unbalanced scheduling, and draft order may seem unsportsmanlike to some, one must consider if these policies serve any broader purpose from a managerial perspective. In other words, do these policies create a better product for consumers, and consequently an advantage for the NFL as a whole?

\section{The Thrill of Sports Entertainment}

Understanding what motivates people to watch competitive sports is not entirely transparent. Nevertheless, in this age of abundance of entertainment choices, it is important that sports organizations recognize and respond to these motivations. For the NFL, an "evolutionary" environment where strong teams continue to get stronger ultimately creating league of a few strong teams and other weak teams with little chance of becoming strong is an undesirable scenario 
for fans (Hamilton Spectator, 2005). Further, consumer behavior studies on sports and game entertainment identify perceived indeterminacy [both process and outcome] (Vosgerau et al., 2006), unexpectedness (Berlyne, 1960; d'Astous and Gagnon, 2007), and "pure entertainment value" (e.g., excitement, dramatic performance and victory) (Passikoff, 2009) as important antecedents to consumer appreciation of a (board) game, live television, and to fan loyalty. While this set of studies is by no means exhaustive, they do point to the importance of excitement, unexpectedness, and indeterminacy (both process and outcome) as important predictive elements in understanding a consumer's choice of entertainment consumption. They, also along with other studies in the sports economic literature, collectively challenge the assumption that sports fans would prefer to watch the same "winners" winning game after game, season after season (e.g., strong football teams consistently outplaying weaker teams) (Hadley et al., 2005; Sanderson and Siegfried, 2003). In sum, the excitement of sporting events comes from not knowing how it will end (Ahn and Lee, 2014).

Given the positive relationship between unpredictability or indeterminacy and the consumers' experience of excitement, it would seem, from a strategic perspective that the NFL should want to "create" as much process and outcome indeterminacy as possible. To achieve this result the NFL has implemented policies that are designed to create competitive balance. Competitive balance in turn helps the NFL to maintain its value with its key stakeholders, mainly fans. Nonetheless, the ultimate result of the intentional implementation of these policies is strategic isomorphism (i.e., increasing similarity of outcomes among different sports teams).

In a fairly substantial review of the sports management literature, Washington and Patterson (2011) provide several examples of the predictive power of institutional theory within this context and demonstrate the appropriateness of institutional theory for understanding the context within which sports organizations operate. Within the current study, institutional theory helps to explain the motivations behind enacting policies that can create competitive balance. Further, if the policies function as intended, the current study may begin to speak to Washington and Patterson's (2011) call for more research on both how different sports leagues evolve over time and why some sports (like the NFL) have remained in a dominant position over time (Hoovers, 2012, Miller, 2012, Easterbrook, 2012, Fendich, 2012).

In the next section we will explore the NFL to determine if strategic isomorphism (as measured by the presence of competitive balance) is indeed one of the characteristics in its competitive environment.
Over the 53 year analysis we expect to find evidence of strategic isomorphism within the NFL as measured by presence of competitive balance. While there is no definitive test for whether the NFL has created competitive balance in the league, certain patterns in the outcomes of games should be seen. Consequent$1 y$, an analysis of the outcomes of games played over multiple seasons is an appropriate basis for the judgment of the presence of competitive balance in the league. If indeed strategic isomorphism exists within the NFL as a first step we expect the following:

Hypothesis 1: The National Football League will have competitive balance within each season.

Although the NFL may have policies which are intended to create competitive balance, these policies could be ineffective (i.e., there is no creation of competitive balance). Further, if the policies are effective, the consequences of said policies should be stable over time. Thus, to see if indeed the policies are effective in "leveling the playing field" and thereby creating similarity in outcomes over time, we expect to find the following pattern:

Hypothesis 2: The National Football League will have competitive balance across multiple seasons.

In other words, if strategic isomorphism (as measured by competitive balance) is present within the NFL, the ultimate result of these policies over multiple seasons will be similarity in the winning percentages across the teams in each season and across seasons, as well as different teams winning the championship each season.

We have chosen to limit our analysis to the NFL. While we recognize this also presents a limitation to the current study, we suspect that garnering a deeper empirical and longitudinal understanding of the phenomenon within this context (as a first step) will allow for a clearer understanding of multi-sports analyses.

\section{Method}

The National Football League's (NFL) official website $^{1}$ was used to obtain a list of Super Bowl (the NFL's championship game) winners, and winning percentage for each team for 53 NFL seasons 19602012. The 1960 season was chosen for the start of the analyses because that season had a significant expansion in the number of teams, from 12 in 1959 to 21 in 1960. For data analyses across seasons we used several different statistical techniques ${ }^{2}$ : Gini Coefficient, Competitive Balance Ratio, Standard Deviation Ratio, Herfindahl-Hirschmann Index, Correlations of Winning Percentages, and Consecutive Winning or Losing Seasons and followed the NFL.com "Team Capsules" (see the Appendix A for a complete list of team histories). 


\section{Results}

Results for Hypothesis 1-Competitive Balance within Seasons

Test 1a: Standard Deviation in Winning Percentage. If competitive balance exists within the NFL, there should be a low standard deviation in winning percentage (PCT) across the teams for each season, which creates close races for the championship among several teams (Balfour and Porter, 1991). A low standard deviation in PCT means that the PCT's tend to cluster near .500 , rather than having some teams win most or all of their games and some teams lose most or all of their games. The standard deviation in PCT was calculated for each NFL season from 1960-2012, and ranged from .15 to .26 , with a mean of .20 across 53 seasons. By decade, the mean standard deviations ranged from .18 to .23 . The results of these analyses are summarized in Table 1 . Across the 53 NFL seasons, extreme levels of team performance are rare; only two teams have won (Miami in 1972, New England in 2007) or lost (Tampa Bay in 1976, Detroit in 2008) all of their games in a season.

Table 1. Mean Standard Deviation in Winning Percentage (PCT), Mean Idealized Standard Deviation in PCT, Mean Ratio of Standard Deviation in PCT to Idealized Standard Deviation in PCT, Mean Gini Coefficient, Competitive Balance Ratio, and Standard Deviation Ratio, By Decade

\begin{tabular}{|c|c|c|c|c|c|}
\hline Decade & $\begin{array}{l}\text { Standard Devi- } \\
\text { ation in PCT }\end{array}$ & $\begin{array}{l}\text { Ratio: Standard Deviation in } \\
\text { PCT/Idealized Standard } \\
\text { Deviation in PCT }\end{array}$ & $\begin{array}{l}\text { Gini Coeffi- } \\
\text { cient }\end{array}$ & $\begin{array}{c}\text { Competitive Bal- } \\
\text { ance Ratio (by } \\
\text { decade) }\end{array}$ & $\begin{array}{l}\text { Standard Devia- } \\
\text { tion Ratio (by } \\
\text { decade) } \\
\end{array}$ \\
\hline 2010's & .20 & 1.56 & .22 & - & - \\
\hline 2000's & .20 & 1.57 & .22 & .84 & .88 \\
\hline 1990’s & .19 & 1.51 & .21 & .84 & .87 \\
\hline 1980’s & .19 & 1.46 & .21 & .87 & .90 \\
\hline 1970's & .21 & 1.61 & .24 & .75 & .77 \\
\hline 1960’s & .23 & 1.68 & .25 & .76 & .79 \\
\hline All Seasons & .20 & 1.56 & .22 & .96 & .95 \\
\hline $\begin{array}{l}\text { More Competi- } \\
\text { tive Balance }\end{array}$ & Closer to 0.00 & Closer to 1.00 & Closer to 0.00 & Closer to 1.00 & Closer to 1.00 \\
\hline
\end{tabular}

Note. All Seasons is all NFL seasons 1960-2012, and 2010's decade is 2010-2012.

Test 1b: Ratio of Standard Deviation in Winning Percentage to Idealized Standard Deviation in Winning Percentage. Another measure of competitive balance compares the standard deviation in PCT with an "idealized" standard deviation in PCT equal to .500 divided by the square root of the number of games in a season (Quirk and Fort, 1992). The closer the ratio of the actual standard deviation in PCT to the idealized standard deviation in PCT is to 1.0, the greater evidence of competitive balance. The ratios ranged from 1.22 to 1.91 , with a mean across 53 seasons of 1.56 . These ratios by decade are shown in Table 1.

Test 1c: Gini Coefficient. The Gini Coefficient has been used extensively in other contexts as a measure of inequality among a set of values (e.g., inequality of income or wealth for a set countries). It has also been used to measure competitive balance (Larsen et al., 2006). If competitive balance exists within the league it will have Gini Coefficients closer to zero. The Gini Coefficients ranged from .17 to .29 , with a mean across 53 seasons of .22. These results by decade are shown in Table 1.

Collectively, these results support Hypothesis 1 . Based on our analysis, competitive balance is present within the NFL within each season across the 53 seasons 1960-2012, when measured by the standard deviation in PCT by season, the ratio of standard deviation in winning percentage to idealized standard deviation in winning percentage, and Gini Coefficients.

\section{Results for Hypothesis 2-Competitive Balance across Multiple Seasons}

Test 2a: Competitive Balance Ratio and Standard Deviation Ratio. From a longitudinal perspective, in addition to within-season measures of competitive balance it is also important to look for evidence of year-to-year fluctuations in team performance (Eckard, 2001). Competitive balance over time means that each team's PCT should converge on .500 over multiple seasons, with each team having some winning and some losing seasons.

Humphreys (2002) suggested using the Competitive Balance Ratio (CBR) which allows a comparison of within team variation in PCT over multiple seasons to within league variation in PCT over multiple teams. The CBR ranges from zero (no competitive balance: the teams have the same winning percentage season after season), to 1.0 (high competitive bal- 
ance: every team has winning and losing seasons). We also calculated a Standard Deviation Ratio (SDR), which we defined as a simple ratio of the average across-season standard deviation to the average across-team standard deviation for a given number of seasons (Noll, 1988; Scully, 1989).

By decade, the CBR's were ranged from .75 to .87 , with a mean across 53 seasons of .96. The SDR's ranged from .77 to .90 , with a mean across all seasons of .95. For 1960-2012, the CBR was .96 and the SDR was .95. These results are summarized in Table 1.

Test 2b: Super Bowl Winners. If competitive balance is present in the NFL, different teams should win the Super Bowl each season, instead of the same or a few teams dominating the league. Of the current 32 NFL teams, eighteen different teams have won the 47 Super Bowls, 14 teams have never won it, and 12 teams have won it multiple times. In the eleven seasons 2002-2012 (with the current 32 teams), eight different teams have won the Super Bowl. No team has won the Super Bowl three times in a row.

Test 2c: Super Bowl Winners' Winning Percentage the Following Season. Since Super Bowl I (1967) through Super Bowl XLVI (2012), the mean PCT of the Super Bowl winning team was .80, and the mean PCT for those teams in the following season was .67. A Paired Samples t-Test showed that these teams' post-Super Bowl PCT was significantly lower, $t(45)=5.04, p<.001$, in the season after winning the championship.

Test 2d: Herfindahl-Hirschman Index. The Herfindahl-Hirschman Index (HHI) has been used as a measure of inequality or concentration of income distribution (Depken, 1999). If one team wins the championship every year in a ten-year span the HHI would be 1.0 (i.e., that team had a "monopoly" on the championship). If ten different teams win the championship in a ten-year span the HHI will be 0.1 . HHI's were calculated for each decade from the 1960 's to the 2000 's, and ranged from .18 to .24 (excluding the 1960's which included only 4 Super Bowls, and the 2010's which included only 3), and for all 47 Super Bowls was .08. The HHI's for conference championships ranged from .10 to .16, and was .05 across 1966-2012. It should be noted that following Owen, et al. (2007), dHHI was also calculated, to adjust for the differing number of teams, using the average number of teams in the NFL in the time period. These results are shown in Table 2.

Table 2. Herfindahl-Hirschman Indices for Super Bowl Winners and Conference Championship Teams, by Decade, 1966-2012 Seasons

\begin{tabular}{|c|c|c|c|c|}
\hline Decade & Number of Super Bowls & $\begin{array}{l}\text { Number of Different Teams Win- } \\
\text { ning Super Bowl }\end{array}$ & $\begin{array}{l}\text { Herfindahl-Hirschman Index } \\
(\mathrm{HHI})\end{array}$ & $\mathrm{dHHI}$ \\
\hline 2010’s & 3 & 3 & .33 & .30 \\
\hline 2000’s & 10 & 7 & .18 & .15 \\
\hline 1990’s & 10 & 7 & .18 & .15 \\
\hline 1980’s & 10 & 6 & .24 & .20 \\
\hline 1970’s & 10 & 6 & .18 & .14 \\
\hline 1960’s & 4 & 3 & .38 & .34 \\
\hline All & 47 & 18 & .08 & .04 \\
\hline Decade & $\begin{array}{c}\text { Number of Conference } \\
\text { Championships } \\
\end{array}$ & $\begin{array}{l}\text { Number of Different Teams Win- } \\
\text { ning Conference Championship }\end{array}$ & $\begin{array}{l}\text { Herfindahl-Hirschman Index } \\
\text { (HHI) }\end{array}$ & $\mathrm{dHHI}$ \\
\hline 2010’s & 6 & 6 & .17 & .14 \\
\hline 2000’s & 20 & 14 & .10 & .06 \\
\hline 1990’s & 20 & 12 & .11 & .08 \\
\hline 1980’s & 20 & 10 & .13 & .09 \\
\hline 1970’s & 20 & 9 & .16 & .12 \\
\hline 1960’s & 8 & 6 & .19 & .15 \\
\hline All & 94 & 28 & .05 & .02 \\
\hline
\end{tabular}

Note. $\mathrm{dHHI}$ is $\mathrm{HHI}$ adjusted for average number of teams in NFL during the time period.

Test 2e: Correlations of Winning Percentage across Seasons. If competitive balance exists in the league, teams will have varying PCT's from season to season (Balfour and Porter, 1991). In other words, when competitive balance is present, how well a team does this season should be only a moderate predictor of how well the team does next season, and a poorer predictor in subsequent seasons (Butler, 1995).
Each NFL team's PCT was correlated with their PCT 1 season later and 2, 3, 4, and 5 seasons after the reference season, starting with 1960. Across all 53 seasons, the mean correlation of PCT with PCT 1 season later was .43. The mean correlation for subsequent seasons was .31 for Season+2, .21 for Season+3, .13 for Season+4, and .10 for Season+5. PCT was a moderate predictor of PCT the following season, and 
a progressively poorer predictor for subsequent seasons. These results are shown in Figure 1 and highlight the low correlation of winning percentage in a given season with winning percentage in subsequent seasons.

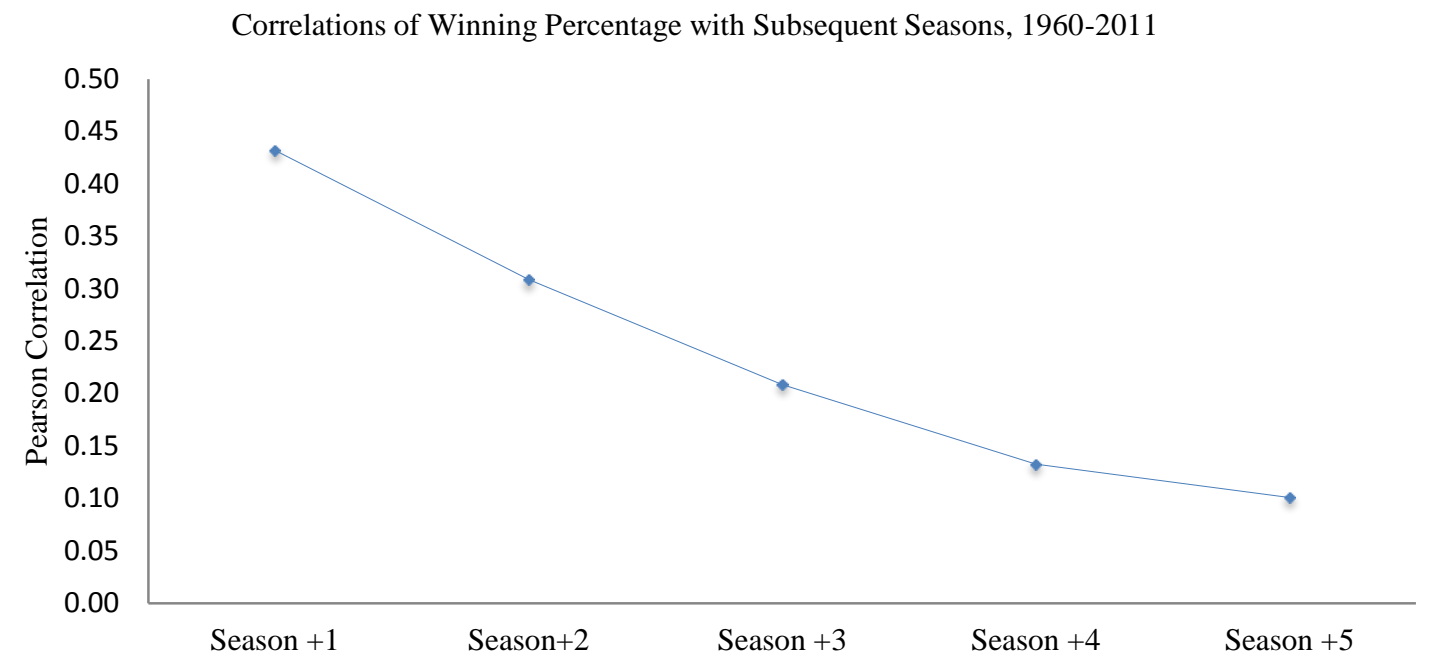

Figure 1. Average Correlations of Winning Percentage with Subsequent Seasons' Winning Percentage, 1960-2012

Test 2f: Consecutive Winning or Losing Seasons. A league with competitive balance will have teams with a low number of consecutive winning seasons and a low number of consecutive losing seasons. From 1960-2012, the mean number of consecutive winning seasons (PCT above .500) was 2.6, with only four teams having had winning streaks longer than 10 years. Conversely, from 1960-2012, the mean number of consecutive losing seasons (PCT below
$.500)$ was 2.5 , but the mode was 1.0 . Only two teams have had losing streaks longer than 10 years. This pattern of results as shown in Figure 2 highlight that long winning streaks and long losing streaks are uncommon for NFL teams, the most common result following a losing season is a winning season, and the most common result following a winning season is a losing season. Collectively, these results support Hypothesis 2.

Frequencies of Consecutive Seasons Above .500 PCT and Below, 1960-2012

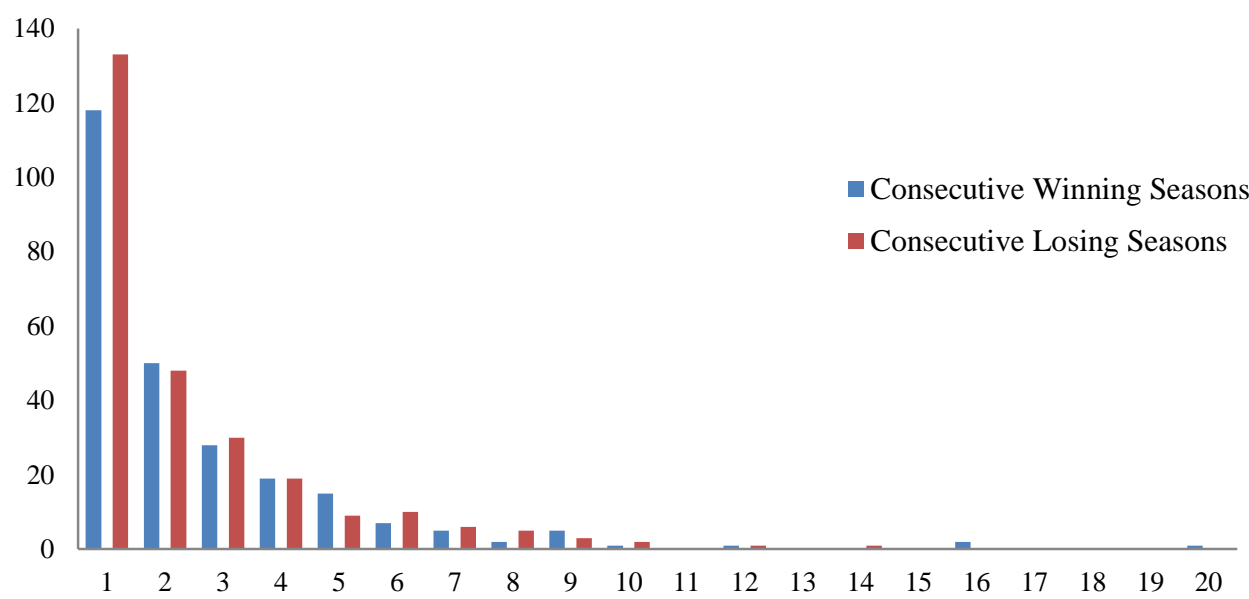

Figure 2. Frequencies of Consecutive Seasons with Winning Percentage Above or Below .500, 1960-2012 
Based on our analysis, the NFL experienced a high degree of similarity in outcomes across 53 seasons 1960-2012, when measured by Competitive Balance Ratio, Standard Deviation Ratio, the diversity of Super Bowl Winners, the significantly lower post Super Bowl winner PCT, the HHI Indices, the moderate correlation of PCT with PCT in the following season and progressively smaller correlations with subsequent seasons, and the low number of consecutive winning or losing seasons.

\section{Discussion}

One of the important elements to maintaining sports fan interest rests in not knowing how each game will end. According to Rottenberg (1956), the nature of the sports industry is that for a league to be successful in selling their entertainment product, the competing teams must be of approximately equal "size," i.e., teams that are of approximately equal strength. Rottenberg (2000) further notes that for any professional team sports "the quality of a game is higher...the more uncertain its outcome before the start of play," and this applies to both individual games and which team will win the championship.

The NFL has intentionally adopted policies to create competitive balance, which makes the teams of equal "size," which in turn creates greater uncertainty in the outcomes of individual games and who will win the championship. While the intentional creation of competitive balance may seem unsportsmanlike by stacking the deck against successful teams, from a strategic perspective, this form of strategic isomorphism has created a highly desirable product for consumers, namely, unpredictability in the outcomes of individual games and championships which over time maintains fan interest in the NFL's entertainment product (Hoovers, 2012; Miller, 2012; Easterbrook, 2012; Fendrich, 2012).

We proposed two hypotheses relating to the presence of competitive balance in the NFL, and found support for both hypotheses. In testing for presence of competitive balance in the NFL, we found a low standard deviation in winning percentage across teams in each season 1960-2012, indicating that the NFL has been a league of teams of nearly equal strength, supporting Hypothesis 1. Each of the individual statistical tests (i.e., the ratio of standard deviation in winning percentage to the "idealized" standard deviation in winning percentage, the Gini Coefficient, the Competitive Balance Ratio, and the Standard Deviation Ratio) point to the same conclusion.

We also found from a longitudinal perspective that the NFL has not been dominated by a few strong teams which win most of the championships. More than half of the NFL's current 32 teams have won a Super Bowl, only 11 teams have won it more than once, and no team has won the Super Bowl three seasons in a row. Super Bowl winning teams have tended to have a lower winning percentage the following season, and Herfindahl-Hirschman Indices showed a low concentration of Super Bowl wins and conference championships among a few teams when calculated by decade and across 1966-2012. NFL teams also have shifting fortunes from season to season, with winning percentage being only a moderate predictor of winning percentage in the following season, and a progressively poorer predictor for subsequent seasons. NFL teams also have tended to have few consecutive winning seasons, and few consecutive losing seasons. These results support Hypothesis 2. To summarize, the tests performed on these longitudinal data suggest the presence of competitive balance in the NFL in each season analyzed and across 53 seasons, which is evidence of strategic isomorphism in the NFL.

This paper makes a number of important contributions. First, it answers the call of Fernández-Alles and Valle-Cabrera (2006) to examine competitive behavior over longer time periods. In this case, the data capture a 53 year time frame. Second, it provides another example of how organizational theories (like institutional theory) can shed light on the strategic and competitive issues underlying a sports organization's competitive environment (Fort and Maxcy, 2003; Washington and Patterson, 2011). In this case, institutional theory has provided some perspective on the motivations underlying the pursuit of competitive balance by the NFL, mainly, that the presence of competitive balance serves as a uniting force among the independently-owned NFL sports organizations as they attempt to compete with the various entertainment choices available to their current and potential fans.

The final contribution is more methodological in nature. The sports economics literature on competitive balance contains a number of ways that it can be measured (e.g., Pivovarnik et al., (2008), Zimbalist (2002), Szymanski (2003)). This paper tests for the presence of competitive balance in the NFL in 10 different ways, including Standard Deviation in Winning Percentage, Ratio of Standard Deviation in Winning Percentage to Idealized Standard Deviation in Winning Percentage, Gini Coefficient, Competitive Balance Ratio, Standard Deviation Ratio, Herfindahl-Hirschman Index, Normalized HerfindahlHirschman Index, Correlations of Winning Percentage Across Seasons, Consecutive Winning Seasons, and Consecutive Losing Seasons. From our analyses, we conclude that competitive balance is multifaceted, 
similar to the five facets of job satisfaction (work itself, pay, promotions, coworkers, supervision) as measured by the Job Descriptive Index (Smith et al, 1975). Consequently, testing for the presence of competitive balance in a sports league requires multiple methods of measurement: within a season, across multiple seasons, which teams win the championship across multiple seasons, and teams having shifting fortunes from season to season. Any one measurement alone may miss one of the essential facets of competitive balance.

\section{Conclusion}

Sports organizations, like all other firms, should have an inherent competitive logic. "Common sense" would argue that if the purpose of playing any game is to win, then it certainly follows that a team owner should recruit and retain the best possible players to try to win games and championships. Consequently, winning teams should bring in more fans, more TV viewers, and more merchandise sales. What we found however, is that the NFL employs a different logic. The collective competitive environment known as the NFL has enacted policies to restrict and control each individual team owner's range of strategic options such that the NFL's teams are equally matched thereby creating an entertainment product that customers continue to demand. The NFL's collective goal of more fans, more branded merchandise sales, more ticket and luxury box sales, and especially more lucrative TV contracts, is achieved through deliberate choices to create homogeneity among the different sports organizations within the league (i.e., strategic isomorphism).

While the current research provides additional longitudinal evidence to the growing body of research on strategic isomorphism, future research in this area may choose to pursue comparative studies across additional competitive contexts (e.g., examining this phenomenon within the sports arena might seek to measure and compare the degree of competitive balance in other professional sports leagues (e.g., National Hockey League, Major League Baseball, etc.) or college sports leagues (e.g., The Big Ten, Southeastern Conference, etc.). Multi-sports comparison studies may provide additional insight on the specific environmental, organizational or stakeholder variables that can lead said sports or leagues to pursue competitive balance (particularly if the phenomenon is not consistent across all sports). The findings of this research also open the door for further empirical investigation of the importance of strategic isomorphism in competitive contexts were the work rules or other significant resource allocation deci- sions are heavily influenced by external constituents (e.g., workforces that have a high percentage of workers belonging to national or international unions, the presence of powerful external stakeholders) (Greenhouse, 2014; Greene, 2012). This second implication has broader potential applications in the areas of political science (e.g., the presence of strategic isomorphism across or within political parties) and any competitive context with a large presence or cross-organizational organized labor.

\section{Notes}

1. www.nfl.com

2. The purpose and application of each of the statistical techniques are described in more detail in the results section.

\section{References}

Abrutyn, S. (2012). Toward A theory of institutional ecology: The dynamics of macro structural space. Review of European Studies, 4(5), 167-180.

Ahn, S. C., \& Lee, Y. H. (2014), Major league baseball attendance: Long-term analysis using factor models. Journal of Sports Economics, 15(5), 1-27.

Balfour, A. and Porter, P. (1991), "The reserve clause in professional sports: Legality and effect on competitive balance", Labor Law Journal, Vol. 42 No. 1, pp. 8-18.

Barney, J. (2001), "Is the resource-based "view" a useful perspective for strategic management research? Yes" Academy of Management Review, Vol. 26 No. 1, pp. 41-56.

Berlyne, D. (1960), Conflict, arousal and curiosity. McGraw-Hill, New York, NY.

Bresser, R. K. F., \& Millonig, K. (2003). Institutional capital: competitive advantage in light of the new institutionalism in organization theory. Schmalenbach Business Review: $Z F B F$, 55(3), 220-241.

Butler, M. (1995), "Competitive balance in Major League Baseball” American Economist, Vol. 39 No. 2, pp. 46-52.

d'Astous, A., and Gagnon, K. (2007), "An inquiry into the factors that impact on consumer appreciation of a board game" Journal of Consumer Marketing, Vol. 24 No. 2, pp. 80-89.

Davis, G. F., \& Marquis, C. (2005). Prospects for organization theory in the early twenty-first century: Institutional fields and mechanisms. Organization Science, 16(4), 332-343.

Deephouse, D. (1996), "Does isomorphism legitimate?" Academy of Management Journal, Vol. 39 No. 4, pp. 1024-1039.

Deephouse, D. and Carter, S. (2005), "An examination of differences between organizational legitimacy and organizational reputation", Journal of Management Studies, Vol. 42 No. 2, pp. 329-360.

Depken, C. (1999), "Free-agency and the competitiveness of Major League Baseball", Review of Industrial Organization, Vol. 14 No. 3, pp. 205-217. 
Easterbrook, G. (2012). "The NFL's total domination of television. ESPN Page 2: Tuesday Morning Quarterback". http://espn.go.com/espn/page2/story/_id/ 7468174/the-nfl-ratings-continue-surge-dominatingall-programing-path (accessed 5 December 2013).

Eckard, E. (2001), "Free agency, competitive balance, and diminishing returns to pennant contention", Economic Inquiry, Vol. 39 No. 3, pp. 430-443.

Endo, M., Flori o, K., Gerber, J., and Sommers, P. (2003), "Does a salary cap improve competitive balance?" Atlantic Economic Journal, Vol. 31 No. 4, pg. 388.

Fendrich, H. (2012). "NFL's ratings, revenue, popularity grow and grow", Fox News. http://www.foxnews.com /sports/2012/02/03/nfls-ratings-revenue-popularitygrow-and-grow/ (accessed 5 December 2013).

Fernández-Alles, M., and Valle-Cabrera, R. (2006), "Reconciling institutional theory with organizational theories", Journal of Organizational Change Management, Vol. 19 No. 4, pp. 503-517.

Fort, R., and Maxcy, J. (2003), "Competitive balance in sports leagues: An introduction" Journal of Sports Economics, Vol. 4 No. 2, pp. 154-160.

Greene, B. (2012), "What changed the Olympics forever", CNN. http://www.cnn.com/2012/07/22/opinion/ greene-olympics-amateurs/ (accessed 16 June 2014).

Greenhouse, S. (2014) "Outsiders, Not Auto Plant, Battle U.A.W. in Tennessee", New York Times, http://www.nytimes.com/2014/01/29/business/outsider s-not-auto-plant-battle-uaw-in-tennessee.html?_r=0 (accessed 16 June 2014).

Grier, K. and Tollison, R. (1994), "The rookie draft and competitive balance: The case of professional football", Journal of Economic Behavior and Organization, Vol. 25 No. 2, pp. 293-298.

Hadley, L., Ciecka, J., and Krautman, A. (2005), "Competitive balance in the aftermath of the 1994 players' strike", Journal of Sports Economics, Vol. 6 No. 4, pp. 379-389.

Hamilton Spectator (2005). "Olympics tosses out baseball, softball", July 9, SP10.

Hoovers (2012). Hoover's company records - In-depth records: National Football League, http://www.lexisnexis.com/hottopics/lnacademic/?shr $=\mathrm{t} \& \mathrm{sfi}=\mathrm{AC} 00 \mathrm{NBGenSrch} \& \mathrm{csi}=3746 \quad(15 \quad$ January 2013).

Humphreys, B. (2002), "Alternative measures of competitive balance in sports leagues", Journal of Sports Economics, Vol. 3 No. 2, pp. 133-148.

Humphreys, B. (2003), "Comments on "Thinking about Competitive Balance."' Journal of Sports Economics, Vol. 4 No. 4, pp. 284-287.

Kahane, L. (2003), "Comments on "Thinking about Competitive Balance."'” Journal of Sports Economics, Vol. 4 No. 4, pp. 288-291.

Larsen, A., Fenn, A., and Spenner, E. (2006), "The impact of free agency and the salary cap on competitive balance in the National Football League", Journal of Sports Economics, Vol. 7 No. 4, pp. 374-390.

Lenten, L. (2008), "Unbalanced schedules and the estimation of competitive balance in the Scottish Premier League", Scottish Journal of Political Economy, Vol. 55 No. 4, pp. 488-508.
McCarthy, M. (2011). "As TV entity, combine following draft's lead", USA Today. http://www.usatoday.com/printedition/sports/2011022 5/mccarthy25_st.art.htm?loc=interstitialskip (accessed 5 December 2013).

Meyer, J., and Scott, W. (1983), Organizational environments: Ritual and rationality, Sage, Beverly Hills, CA.

Miller, P. (2012), "An overview of NFL revenues and costs" in Coats, D. (Series Ed.) and Quin, K. G. (Vol. Ed.), The Economics of the National Football League: The State of the Art, Sports Economics, Management and Policy, Vol. 2, pp. 55-77.

Neale, W. (1964), "The peculiar economics of professional sports: A contribution to the theory of the firm in sporting competition and in market competition", Quarterly Journal of Economics, Vol. 78 No. 1, pp. 1-14.

Noll, R. G. (1988). "Professional basketball", Working paper, Studies in Industrial Economics Paper No. 144. Stanford University, Stanford, CA.

Owen, P., Ryan, M., and Weatherston, C. (2007), "Measuring competitive balance in professional sports using the Herfindahl-Hirshman Index", Review of Industrial Organization, Vol. 31, pp. 289-302.

Passikoff, R. (2009). "2009 Sports Fan Loyalty Index finds MLB in third spot, ahead of hockey, baseball is the only place in life where a sacrifice is really appreciated."

http://www.visibilitypr.com/Press_Room/Entries/2009 14/2_2009_Sports_Fan_Loyalty_Index_Finds_MLB_i n_Third_Spot,_Ahead_of_Hockey.html (accessed 5 December 2013).

Peteraf, M. (1993), "The cornerstones of competitive advantage: A resource-based view", Strategic Management Journal, Vol. 14 No. 3, pp. 179-191.

Pivovarnik, T., Lamb, R., Zuber, R. and Gandar, J. (2008), "Competitive balance and fan interest in the National Football League", Journal of Economics and Economic Education Research, Vol. 9 No.2, pp. 75-98.

Porter, M. (1996), "What is strategy?" Harvard Business Review, Vol. 74, No. 6, pp. 61-78.

Quirk, J. (2004), "College football conferences and competitive balance", Managerial and Decision Economics, Vol. 25 No. 2, pp. 63-75.

Quirk, J., and Fort, R. (1992), Pay dirt. Princeton University Press: Princeton, NJ.

Rottenberg, S. (1956), "The baseball players' labor market", Journal of Political Economy, Vol. 64 No.3, pp. 242-258.

Rottenberg, S. (2000), "Resource allocation and income distribution in professional team sports", Journal of Sports Economics, Vol. 1, No. 1, pp. 11-20.

Sanderson, A. (2002), "The many dimensions of competitive balance", Journal of Sports Economics, Vol. 3 No. 2, pp. 204-228

Sanderson, A., and Siegfried, J. (2003), "Thinking about competitive balance", Journal of Sports Economics, Vol. 4 No. 4, pp. 255-279.

Schmidt, M. (2001), "Competition in Major League Baseball: The impact of expansion", Applied Economics Letters, Vol. 8 No. 1, pp. 21-26. 
Schmidt, M., and Berri, D. (2001), "Competitive balance and attendance: The case of Major League Baseball", Journal of Sports Economics, Vol. 2 No. 2, pp. 145-167.

Scully, G. W. (1989), The business of major league baseball. University of Chicago Press: Chicago, IL.

Smith, P., Kendall, L., and Hulin, C. (1975), The measurement of satisfaction in work and retirement. Bowling Green State University, Bowling Green, $\mathrm{OH}$.

Szymanski, S. (2003), "The economic design of sporting contests", Journal of Economic Literature, Vol. 41 No. 4, pp. 1137-1187.

Utt, J., and Fort, R. (2002), "Pitfalls to measuring competitive balance with Gini coefficients", Journal of Sports Economics, Vol. 3 No. 4, pp. 367-373.
Vosgerau, J., Wertenbroch, K. and Carmon, Z. (2006), "Indeterminacy and live television", Journal of Consumer Research, Vol. 32 No. 4, pp. 487-495.

Washington, M. and Patterson, K. (2011), "Hostile takeover or joint venture: Connections between institutional theory and sport management research", Sport Management Review, Vol. 14 No. 1, pp. 1-12.

Zimbalist, A. (2002), "Competitive balance in sports leagues: An introduction", Journal of Sports Economics, Vol. 3 No. 2, pp. 111-121.

Zimbalist, A. (2003), "Competitive balance conundrums: Response to Fort and Maxcy's comment", Journal of Sports Economics, Vol. 4 No. 2, pp. 161-163. 